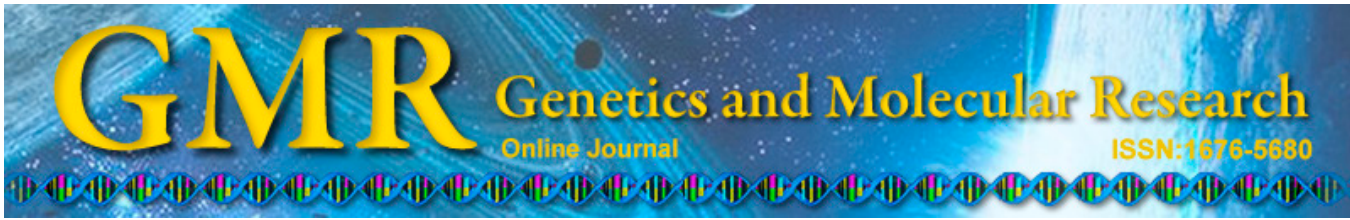

\title{
Gene expression profiles of the heterotrophic microalga Chlorella pyrenoidosa F-9
}

\author{
X. Sun ${ }^{1}$, N.J. Xu' ${ }^{1}$, L.Z. Jiang', W. Hu' ${ }^{1}$, M.H. Fan ${ }^{1}$ and Z.M. Liu ${ }^{2}$ \\ ${ }^{1}$ Key Laboratory of Marine Biotechnology of Zhejiang Province, \\ School of Marine Sciences, Ningbo University, Zhejiang Ningbo, China \\ ${ }^{2}$ Department of Biology, Eastern New Mexico University, Portales, NM, USA \\ Corresponding author: X. Sun \\ E-mail: sunxue@nbu.edu.cn
}

Genet. Mol. Res. 13 (4): 8411-8420 (2014)

Received August 16, 2013

Accepted December 9, 2013

Published October 20, 2014

DOI http://dx.doi.org/10.4238/2014.October.20.17

\begin{abstract}
A strain of the microalga Chlorella pyrenoidosa F-9 in our laboratory showed special characteristics when transferred from autotrophic to heterotrophic culture. In order to elucidate the possible metabolic mechanism, the gene expression profiles of the autonomous organelles in the green alga $C$. pyrenoidosa under autotrophic and heterotrophic cultivation were compared by suppression subtractive hybridization technology. Two subtracted libraries of autotrophic and heterotrophic $C$. pyrenoidosa F-9 were constructed, and 160 clones from the heterotrophic library were randomly selected for DNA sequencing. Dot blot hybridization showed that the ratio of positivity was $70.31 \%$ from the 768 clones. Five chloroplast genes $(f t s \mathrm{H}, p s b \mathrm{~B}, r b c \mathrm{~L}, a t p \mathrm{~B}$, and infA) and two mitochondrial genes (cox2 and nad6) were selected to verify their expression levels by real-time quantitative polymerase chain reaction. Results showed that the seven genes were abundantly expressed in the heterotrophic culture. Among the seven genes, the least increment of gene expression was $f t s \mathrm{H}$, which was expressed 1.31-1.85-fold higher under heterotrophy culture than under autotrophy culture, and the highest increment was $p s b \mathrm{~B}$, which increased 28.0739.36 times compared with that under autotrophy conditions. The expression levels of the other five genes were about 10 times higher
\end{abstract}


in heterotrophic algae than in autotrophic algae. In inclusion, the chloroplast and mitochondrial genes in C. pyrenoidosa F-9 might be actively involved in heterotrophic metabolism.

Key words: Chlorella pyrenoidosa; Heterotrophy; Autotrophy; Suppression subtractive hybridization; Expression profile

\section{INTRODUCTION}

Chlorella belongs to phylum Chlorophyta, class Trebouxiophyceae, and family Chlorellaceae. Many species of Chlorella are important economic microalgae containing high contents of polysaccharides, glycoproteins, and Chlorella growth factor. They are widely used in the production of pharmaceuticals, processing of foods, and aquaculture industry (Jeong et al., 2009). In the scientific research, Chlorella has attracted the researchers' attention in its chloroplast development, genome, and photosynthesis (Wakasugi et al., 1997; Blanc et al., 2010; Eckardt, 2010).

The photosynthetic system of Chlorella is similar to that of higher plants, but some species of Chlorella can be cultured under either autotrophic or heterotrophic conditions. Some differences exist in the algal growth and biochemical composition under different culture conditions. Many studies have focused on the optimization of culture conditions for the production of lipids in heterotrophic and mixotrophic Chlorella (Shen et al., 2010; Ngangkham et al., 2012). Little is known about the molecular basis of heterotrophic metabolism and the related gene expression profiles in Chlorella (Bumbak et al., 2011).

When the culture conditions for Chlorella are changed from autotrophic to heterotrophic, key heterotrophic metabolism proteins, such as glucose transporter, are expressed abundantly (Sauer and Tanner, 1989), and the expression of other proteins and pigments in the chloroplast and mitochondria are also changed. Most of heterotrophic Chlorella become yellow because their chlorophyll and lutein contents changed (Shi et al., 1997; Shen et al., 2010). In our laboratory, a strain of C. pyrenoidosa F-9 was yellow-green in autotrophy and dark green in heterotrophy (Figure 1). The color changes indicated the high synthetic activities in the chloroplasts; therefore, it is interesting to investigate the gene expression patterns of the autonomous organelles (chloroplasts and mitochondria) between the autotrophic and heterotrophic Chlorella. In this study, suppression subtractive hybridization (SSH), dot blot hybridization, and real-time quantitative polymerase chain reaction (RT-qPCR) techniques were employed to screen the genes specifically expressed in the heterotrophic C. pyrenoidosa F-9.

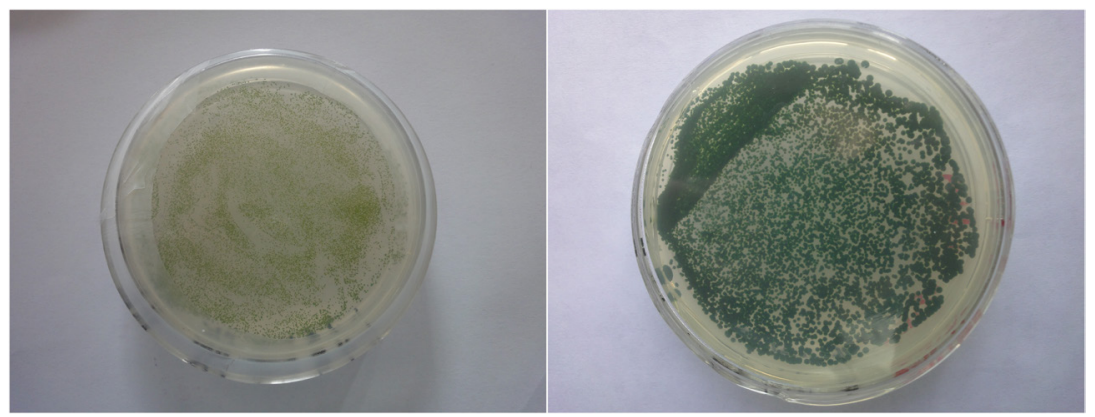

Figure 1. Chlorella pyrenoidosa grown under autotrophic (left) and heterotrophic (right) conditions. 


\section{MATERIAL AND METHODS}

\section{Algal culture}

The alga C. pyrenoidosa F-9 was originally purchased from the Institute of Hydrobiology, Chinese Academy of Sciences, in February 2006. The sterile and monoclonal alga was obtained by repeated passage and antibiotic treatments. The algae from the same clone were separately cultured in autotrophic and heterotrophic conditions. The autotrophic alga was cultured in Knop medium with a light intensity of $40 \mu \mathrm{mol} \cdot \mathrm{m}^{-2} \cdot \mathrm{s}^{-1}$, and in a 12-h light-12-h dark cycle. The heterotrophic alga was cultured in Knop medium plus $10.0 \mathrm{~g} / \mathrm{L}$ glucose and kept in the dark. The culture temperature was $25^{\circ} \mathrm{C}$.

\section{Reagents and chemicals}

Total RNA was extracted by Trizol reagent (Invitrogen Life Technology, USA). The SMART PCR cDNA synthesis kit and PCR-select cDNA subtraction kit were obtained from Clontech Laboratories, Inc. Dot blots were carried out by Shanghai OE Biotech Co., Ltd. using the radioisotope $\alpha-\mathrm{P}^{32}$-dATP. PrimeScript RT reagent kit with gDNA Eraser and SYBR Premix ExTaq for RT-qPCR were purchased from Takara Biotechnology (Dalian) Co., Ltd. Primers for seven target genes $(r b c \mathrm{~L}, f t s \mathrm{H}, p s b \mathrm{~B}, \operatorname{nad} 6, a t p \mathrm{~B}, \operatorname{cox} 2$, and $\inf \mathrm{A})$ and the internal standard $\beta$-actin gene were synthesized by Invitrogen Corporation Shanghai Representative Office, and the nucleotide sequences of the primers were listed in Table 1.

\begin{tabular}{|c|c|c|c|}
\hline Gene names & Primer names & Primer sequence $\left(5^{\prime}-3^{\prime}\right)$ & Length (bp) \\
\hline \multirow[t]{2}{*}{ actin } & actin234 & CGGCTACTCCTTCACCACCA & 113 \\
\hline & actin346 & AGGAGTTGAGCGAGGTCTGC & \\
\hline \multirow[t]{2}{*}{$r b c \mathrm{~L}$} & rbcL53 & ATACCGTGAGGAGGACCTTGGA & 194 \\
\hline & rbcL246 & CCAGGTGAAGAAAACCAATACA & \\
\hline \multirow[t]{2}{*}{$f t s \mathrm{H}$} & $f t s \mathrm{H} 120$ & ACAAAGTGACCGAAATCCAGAA & 129 \\
\hline & $f t s \mathrm{H} 248$ & TTACGAATTGGGAGACTAGAAG & \\
\hline \multirow[t]{2}{*}{$p s b \mathrm{~B}$} & psbB9 & CACCGTCTGATTGAAGAGTTGC & 187 \\
\hline & psbB195 & GATGTTCCTTTCCGTCGTTCTG & \\
\hline \multirow[t]{2}{*}{ nad 6} & nad90 & TTTCAATGCTGCGGGATTACTC & 173 \\
\hline & $\operatorname{nad} 262$ & CTCCACCGATTGGTAAATAGCG & \\
\hline \multirow{2}{*}{$\operatorname{atp} \mathrm{B}$} & atpB215 & GTTTCGTTCAAGCTGGTTCT & 105 \\
\hline & atpB319 & GTTCTTGTAAGCCACCCATT & \\
\hline \multirow[t]{2}{*}{$\cos 2$} & $\operatorname{cox} 250$ & GAAGTGGATAATCGTATGGTTG & 115 \\
\hline & $\operatorname{cox} 364$ & CTGCATCACATTTTGCTCCTAA & \\
\hline \multirow[t]{2}{*}{$\inf \mathrm{A}$} & inf332 & TTGGCGTTGTTTATGTTTTGGG & 191 \\
\hline & inf522 & AATCAAGAAGTTTGTTCCCACC & \\
\hline
\end{tabular}

\section{Establishment of SSH libraries}

Total RNAs from the autotrophic and heterotrophic algae were extracted and converted into cDNA using the SMART PCR cDNA synthesis kit. The autotrophic algal cDNAs were used as driver and the heterotrophic algal cDNAs were used as tester. The forward subtracted library was established after two rounds of PCR. Likewise, the reverse subtracted library was established after the tester and driver cDNAs were exchanged. 


\section{Dot blot}

Three hundred eighty-four white clones from each subtracted library were randomly selected to dot four pieces of nylon membrane. The digested and purified PCR products after two rounds of subtracted PCR were labeled by $\alpha-\mathrm{P}^{32}$-dATP and used as probes including autotrophic probe $\mathrm{Z} 1$ and heterotrophic probe $\mathrm{Y} 2$. After pre-blotting and blotting, the radioactivity was detected, and some positive clones were sequenced by Shanghai OE Biotech and Invitrogen Corporation (Shanghai).

\section{RT-qPCR analysis}

Three time points (10:00, 13:00, and 16:00) in the autotrophic culture period were used to analyze the gene expression profiles, which were marked as Z10, Z13, and Z16, respectively. The corresponding three time points in the heterotrophic period were labeled as Y10, Y13, and Y16. Total RNAs were extracted, and their qualities and quantities were determined by agarose gel electrophoresis and NanoDrop 1000 spectrophotometry. To eliminate the trace genomic DNA contamination, an RT reagent kit with gDNA Eraser was used. The total RTqPCR volume was $20 \mu \mathrm{L}$, which included $10 \mu \mathrm{L} 2 \mathrm{X}$ SYBR Premix Ex Taq, $0.4 \mu \mathrm{L} 10 \mu \mathrm{M}$ forward and reverse primers, $2 \mu \mathrm{L}$ RT reaction mixture, and $7.2 \mu \mathrm{LddH}_{2} \mathrm{O}$. The RT-qPCR protocol was as follows: pre-denaturation at $95^{\circ} \mathrm{C}$ for $3 \mathrm{~min}$ and 40 cycles of denaturation at $95^{\circ} \mathrm{C}$ for $10 \mathrm{~s}$, annealing at $55^{\circ} \mathrm{C}$ for $20 \mathrm{~s}$, and elongation at $72^{\circ} \mathrm{C}$ for $30 \mathrm{~s}$. PCRs were performed three times for each sample. The Rotor-Gene Q serial software 2.0.2 (Rotor-Gene 6000 PCR) was used for data analysis.

\section{RESULTS}

\section{SSH library construction and quality analysis}

High-quality RNA samples were obtained from autotrophic and heterotrophic algae (Figure 2). The ratio of $28 \mathrm{~S}$ and $18 \mathrm{~S}$ rRNA brightness was about 1:1, and no obvious DNA bands were observed. Based on the protocol from the kit, the second PCR amplifications were carried out, and the results were shown in Figure 3. The sizes of cDNAs ranged from 500 to $2000 \mathrm{bp}$, with several prominent bands appearing on the gel. To detect the length of inserted fragments, some clones were selected from the forward and reverse library. Electrophoresis results showed that most fragments varied from 500 to $1000 \mathrm{bp}$ in length, and fragments longer than $1000 \mathrm{bp}$ or shorter than $250 \mathrm{bp}$ were few (Figure 4).

Generally, there exists a certain proportion of false positives in the SSH results. In order to test the true-positive clones, dot blot analysis was conducted, and the results were shown in Figure 5. The proportion with significant differences in radioactivity was about $70.31 \%$; 540 of 768 clones were true positive ones.

\section{DNA sequencing}

A total of 160 available sequences were obtained after the random sequencing from the heterotrophic subtracted library. Most of the known sequences were for different types of 
rRNA and ribosomal protein. Other sequences included ATP synthase subunits $(a t p \mathrm{H}$, atpI, $a t p \mathrm{~F}$, and $a t p \mathrm{~B})$, protochlorophyllide reductase subunit (chlB), $\mathrm{CP} 47$ protein coding gene ( $p s b \mathrm{~B})$, cytochrome oxidase subunit (cox2 and $\operatorname{cox} 3)$, cell division protein $\mathrm{FtSH}$ gene $(f t s \mathrm{H})$ and NADH dehydrogenase subunits ( $\operatorname{ad} 6$ and nad4L). These non-redundant sequences were listed in Table 2, in which cytochrome oxidase (cox) and NADH dehydrogenase came from the mitochondria, and the rest came from chloroplasts.

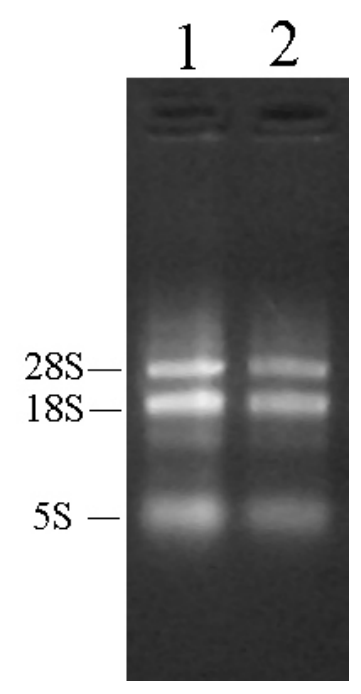

Figure 2. Electrophoresis of total RNA. Lane $1=$ RNA from autotrophic alga; lane $2=$ RNA from heterotrophic alga.

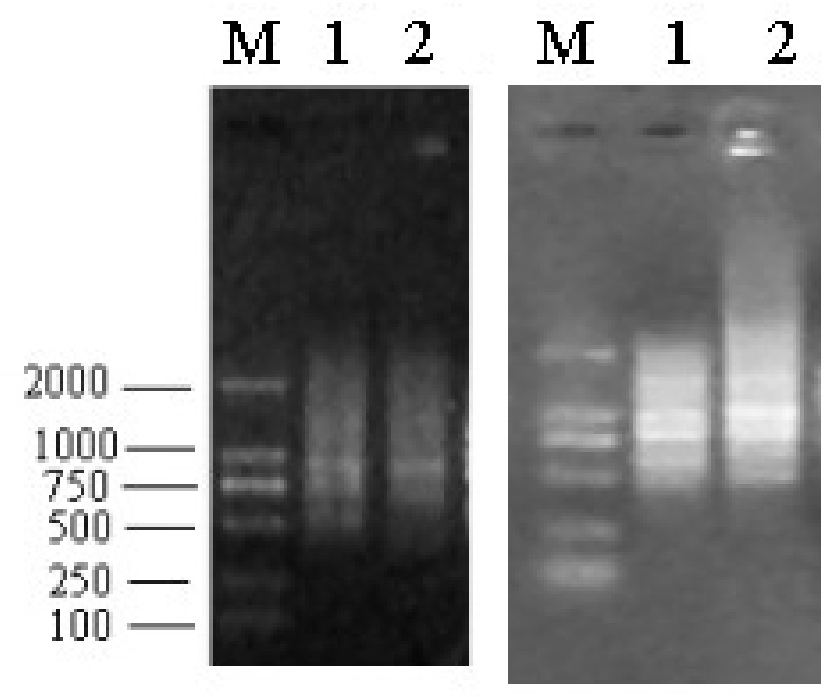

Figure 3. Polymerase chain reaction products of the autotrophic (left) and heterotrophic (right) of Chlorella pyrenoidosa (lane $M=$ DL2000 DNA marker; lane 1 = subtracted cDNA; lane 2 = unsubtracted cDNA). 

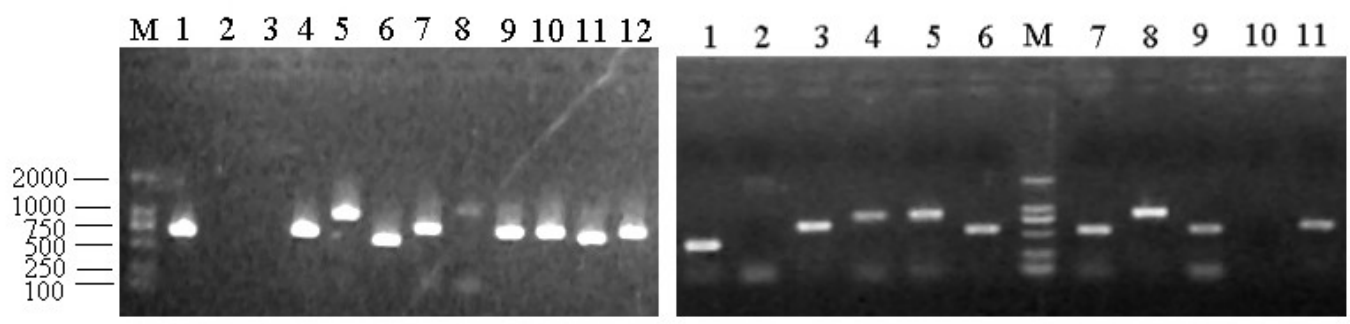

Figure 4. PCR detection of inserted fragments in the autotrophic (left) and heterotrophic (right) subtractive libraries (lane $M=$ DL2000 DNA marker; lanes 1-12 = distinct randomly selected clones in the subtractive library).

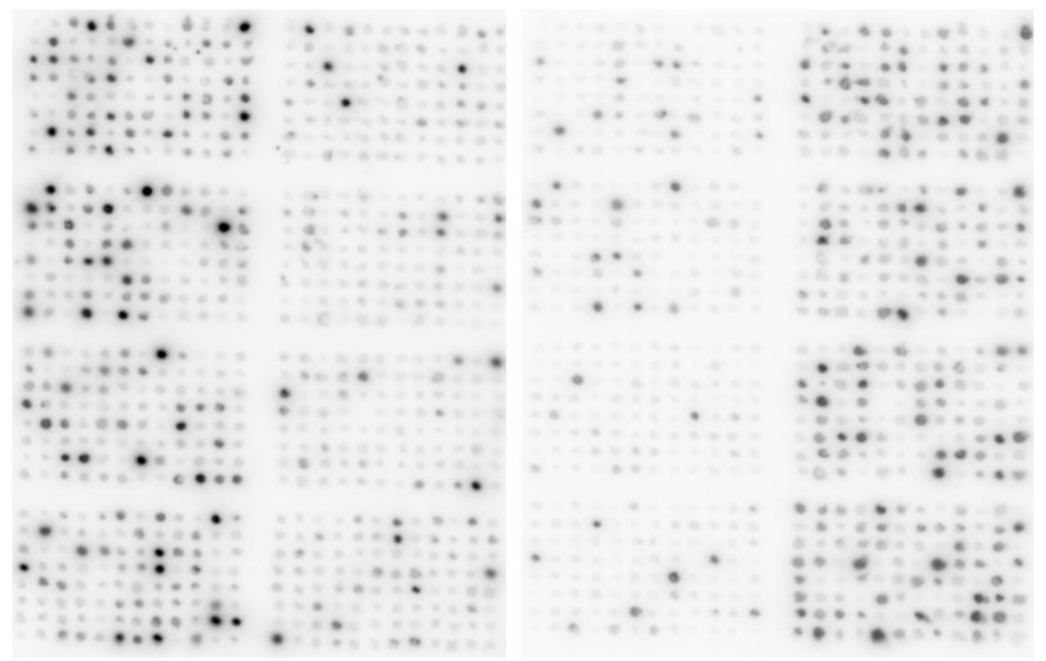

Figure 5. Results of dot blot hybridization by the autotrophic probe Z1 (left) and heterotrophic probe Y2 (right).

Table 2. Partial sequenced clones and their putative similar genes.

\begin{tabular}{|c|c|c|c|c|c|}
\hline Clone number & Length (bp) & Putative similar genes & E-value & Identity $(\%)$ & GenBank accession No. \\
\hline 03 & 713 & ATP synthase CF0 C chain subunit III $(a t p H)$ & $3 e-112$ & 90 & AB001684 \\
\hline 08 & 981 & Cytochrome oxidase, subunit III ( $\operatorname{cox} 3)$ & 2e-104 & 77 & U02970 \\
\hline 26 & 938 & NADH dehydrogenase, subunit 4L (nad4L) & $6 e-66$ & 78 & U02970 \\
\hline 37 & 324 & Rubisco large subunit $(r b c \mathrm{~L})$ & $4 e-164$ & 100 & EU038285 \\
\hline 39 & 970 & Cell division protein FtsH ( fts $\mathrm{H}$ ) & $6 e-28$ & 76 & AB001684 \\
\hline 46 & 622 & $p s b \mathrm{~B}$ & 0 & 89 & AB001684 \\
\hline 48 & 493 & RNA polymerase $\beta$ subunit & $3 e-16$ & 76 & СР000117 \\
\hline 69 & 883 & NADH dehydrogenase subunit 6 (nad6) & $5 e-67$ & 70 & AB251495 \\
\hline 75 & 479 & ATP synthase CF0 subunit IV (atpI) & $9 e-149$ & 84 & AB001684 \\
\hline 100 & 706 & $\mathrm{H}^{+}$-transporting ATPase subunit 9 & $4 \mathrm{e}-66$ & 85 & U02970 \\
\hline B3 & 548 & Cytochrome oxidase subunit II ( $\operatorname{cox} 2)$ & $4 e-173$ & 88 & AY500837 \\
\hline $\mathrm{C} 7$ & 399 & ATP synthase CF0 B chain subunit I (atpF) & $2 \mathrm{e}-118$ & 86 & AB001684 \\
\hline E6 & 371 & $\operatorname{atp} \mathrm{B}$ & $2 \mathrm{e}-143$ & 83 & EF113516 \\
\hline F5 & 803 & Initiation factor IF-1 (infA) & 1e-79 & 89 & AB001684 \\
\hline S1 & 421 & Protoyllide reductase subunit (chlB) & $2 \mathrm{e}-86$ & 88 & AY331983 \\
\hline 14 & 652 & $30 \mathrm{~S}$ ribosomal protein $\mathrm{S} 2$ (rps 2$)$ & $3 e-163$ & $82(583)$ & AB001684 \\
\hline 85 & 677 & Cytochrome oxidase I ( $\operatorname{cox} 1)$ & $3 e-75$ & $78(362)$ & AY129174 \\
\hline
\end{tabular}




\section{Gene expression profiles by RT-qPCR analysis}

To confirm the gene expression in heterotrophic Chlorella, RT-qPCR was performed. Seven genes including $r b c \mathrm{~L}$ (clone 37), cell division gene $f t s \mathrm{H}$ (clone 39), $p s b \mathrm{~B}$ (clone 46), NADH dehydrogenase subunit nad6 (clone 69), atpB (clone E6), cox2 (clone B3), and initiation factor infA (clone F5) were selected for RT-qPCR. The $\beta$-actin gene was used as the internal standard (Machida et al., 2008). The length of amplified PCR fragments ranged from 100 to $200 \mathrm{bp}$.

The three time points of the autotrophic light cycle (Z10, Z13, and Z16) and three time points of the heterotrophic cycle (Y10, Y13, and Y16) were selected to compare the gene expression changes. Results showed that all seven genes had higher expression in the three time points of heterotrophy than in the three time points of autotrophy. If the expression quantities of each gene at $\mathrm{Z} 10$ were set as 1.0, then, fts $\mathrm{H}$ expression had the least change among the seven genes; its expression was 1.31-1.85-fold higher in heterotrophy than in autotrophy (Figure 6A). The expressions of $p s b \mathrm{~B}$ and $c o x 2$ were the highest, and they were expressed 28.07-39.36- and 11.2824.57 -fold in heterotrophy than in autotrophy, respectively (Figure 6B and C). The expression levels of the other five genes in the heterotrophic alga were about 10-fold higher than those in the autotrophic alga (Figure 6D-G).

A

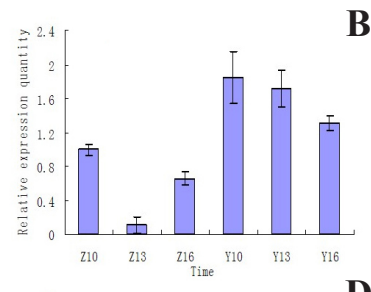

C

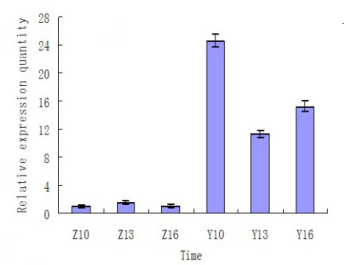

$\mathbf{E}$

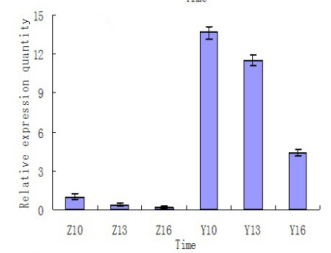

G

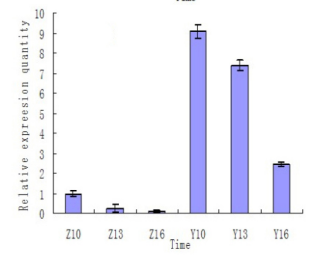

B

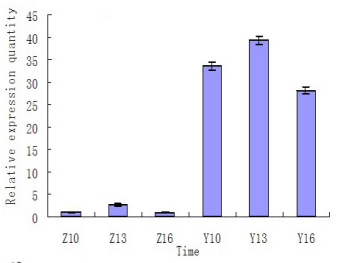

$\mathbf{D}$

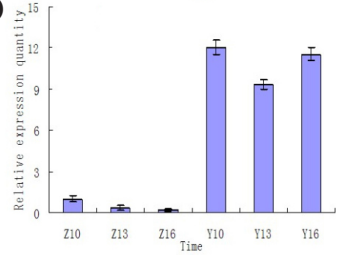

F

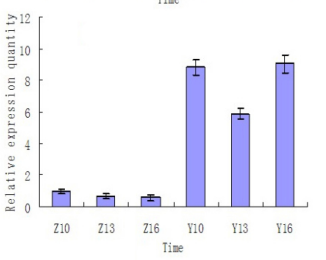

Figure 6. Expression profiles of the seven selected genes under the autotrophic and heterotrophic culture conditions. A.-G. represents $f t s \mathrm{H}, p s b \mathrm{~B}, \operatorname{cox} 2, r b c \mathrm{~L}, n a d 6, a t p \mathrm{~B}$, and inf A, respectively; $\mathrm{Z} 10, \mathrm{Z} 13$, and $\mathrm{Z} 16$ represent the three time points $(10: 00,13: 00$ and 16:00) in the autotrophic cultures; and Y10, Y13 and Y16 represent the three time points $(10: 00,13: 00$ and 16:00) in the heterotrophic cultures. 
Different change tendencies were shown in Figure 6 during the 12-h culture period. In the autotrophic culture, the expression levels of $r b c \mathrm{~L}, \operatorname{nad} 6$, $a t p \mathrm{~B}$, and $\inf \mathrm{A}$ showed a descending trend at the three time points of Z10, Z13, and Z16. The expression of $p s b \mathrm{~B}$ and $\operatorname{cox} 2$ increased and then decreased, while the expression of $f t s \mathrm{H}$ decreased and then increased. In the heterotrophic cultivation, the change tendencies of $f t s \mathrm{H}, \operatorname{nad} 6$, and $\inf \mathrm{A}$ were descending; $c o x 2, r b c \mathrm{~L}$, and $a t p \mathrm{~B}$ expression decreased and then increased; and $p s b \mathrm{~B}$ expression increased and then decreased.

\section{DISCUSSION}

The SSH technique is an effective method to screen and isolate differentially expressed cDNA sequences. The principle of the SSH technique is to remove the common abundant sequences in the compared samples to enrich the differentially expressed sequences. The SSH technique has been widely used in the studies of cell differentiation, development, and cancer diagnosis (Badapanda, 2013). The investigation of SSH technology in algae has increased year by year. In the green alga Chlamydomonas reinhardtii, a sequence similar to bacterial iron hydrogenase was isolated by the SSH method (Happe and Kaminski, 2002). The transcript profiling of Chlorella in the heterotrophy to photoautotrophy transition was studied using the SSH method (Fan et al., 2012). For the green alga Acetabularia acetabulum, expressed sequence tags were used to compare the adult phase and the juvenile phase with a technology that was similar to SSH (Henry et al., 2004). The SSH technique was used in the analysis of gene expression in calcifying and noncalcifying cultures of the marine microalga Emiliania huxleyi strain 1516 (Nguyen et al., 2005).

Heterotrophic algae showed a great difference from the autotrophic algae in the physiological and biochemical characteristics. Researchers were concerned about the application and development of heterotrophic Chlorella for bio-oil or lutein production (Miao and Wu, 2004; O'Grady and Morgan, 2011; Jeon et al., 2014), but only genes such as HUP1 transporter, glyceraldehyde 3-phosphate dehydrogenase, and ATP/ADP translocation were found to be abundantly expressed after treatment with glucose (Saucer and Tanner, 1989; Hilgarth et al., 1991).

In contrast to the above research, we focused on the gene expression profiles in chloroplasts and mitochondria under heterotrophic cultivation. Most of these sequenced genes were related to protein synthesis (30S ribosomal protein) and energy metabolism (cox and nad). In order to test the authenticity of the SSH method, seven genes in chloroplasts and mitochondria were used for further RT-qPCR verification. We used the reverse transcription kit with gDNA eraser to remove trace DNA contamination in the total RNA. The RT-qPCR results showed that the expression of all seven genes increased in the heterotrophic culture. Most of the increases were close to or higher than 10-fold.

Microalgae cultured under different conditions expressed different metabolism pathways and related key enzymes, and there was also a series of corresponding adaptations in chloroplasts and mitochondria to accomplish growth and other activities (Perez-Garcia et al., 2011). When C. pyrenoidosa F-9 was cultured under autotrophic and heterotrophic conditions, the highest growth rate of the heterotrophic algae is about 19 times that of the autotrophic algae (Wu X et al., unpublished data). This means that the autonomous organelles in the algae may adapt their functions and metabolism pathways for energy production and growth, and the related gene expression also changes for adaptation. Of the seven genes that were tested 
by RT-qPCR, five genes ( $f t s \mathrm{H}, \operatorname{cox} 2, \operatorname{nad} 6, \operatorname{atp} \mathrm{B}$, and $\inf \mathrm{A})$ are related to cell metabolism and energy conversion. It is easy to understand why these genes are abundantly expressed in heterotrophic algae. However, the $r b c \mathrm{~L}$ and $p s b \mathrm{~B}$ genes also had increased their expression levels under the heterotrophic conditions. The $r b c \mathrm{~L}$ gene, which encodes the large subunit of ribulose 1,5-bisphosphate carboxylase/oxygenase, is mainly related to photosynthesis, but it is a lightindependent protein that is related to dark reactions. The gene is primarily involved in carbon fixation, but it has a putative additional function in lipid acid metabolism. This gene was reported to be expressed in non-photosynthetic broomrape Lathraea, some species of Harveya, Orobanche corymbosa, and $O$. fasciculata; it also has a putative function in myco-heterotrophic Aneura mirabilis, but expression analysis is currently unavailable (Delavault et al., 1995; Wolfe and dePamphilis, 1997; Wicke et al., 2011). The $p s b \mathrm{~B}$ gene encodes the photosystem II P680 chlorophyll A apoprotein (CP-47 protein). Because all the heterotrophic algae are completely cultured in the dark and provided with glucose in the medium, the heterotrophy in this experiment should be complete. The reason for this phenomenon needs to be explored.

\section{ACKNOWLEDGMENTS}

Research supported by the National Natural Science Foundation of China (\#30700610), the Natural Science Foundation of Zhejiang Province (\#LY13D060007), the Innovative Group Project of Zhejiang Province (\#2009R50012-06), the International Cooperation Funding of Ningbo City (\#2010D10012), and the K.C. Wong Magna Fund from Ningbo University.

\section{REFERENCES}

Badapanda C (2013). Suppression subtractive hybridization (SSH) combined with bioinformatics method: an integrated functional annotation approach for analysis of differentially expressed immune-genes in insects. Bioinformation 9: 216-221

Blanc G, Duncan G, Agarkova I, Borodovsky M, et al. (2010). The Chlorella variabilis NC64A genome reveals adaptation to photosymbiosis, coevolution with viruses, and cryptic sex. Plant Cell 22: 2943-2955.

Bumbak F, Cook S, Zachleder V, Hauser S, et al. (2011). Best practices in heterotrophic high-cell-density microalgal processes: achievements, potential and possible limitations. Appl. Microbiol. Biotechnol. 91: 31-46.

Delavault P, Sakanyan V and Thalouarn P (1995). Divergent evolution of two plastid genes, rbcL and atpB, in a nonphotosynthetic parasitic plant. Plant Mol. Biol. 29: 1071-1079.

Eckardt NA (2010). The Chlorella genome: big surprises from a small package. Plant Cell 22: 2924.

Fan J, Cui Y, Huang J, Wang W, et al. (2012). Suppression subtractive hybridization reveals transcript profiling of Chlorella under heterotrophy to photoautotrophy transition. PLoS One 7: e50414.

Happe T and Kaminski A (2002). Differential regulation of the Fe-hydrogenase during anaerobic adaptation in the green alga Chlamydomonas reinhardtii. Eur. J. Biochem. 269: 1022-1032.

Henry IM, Wilkinson MD, Hernandez JM, Schwarz-Sommer Z, et al. (2004). Comparison of ESTs from juvenile and adult phases of the giant unicellular green alga Acetabularia acetabulum. BMC Plant Biol. 4: 3.

Hilgarth C, Sauer N and Tanner W (1991). Glucose increases the expression of the ATP/ADP translocator and the glyceraldehyde-3-phosphate dehydrogenase genes in Chlorella. J. Biol. Chem. 266: 24044-24047.

Jeong H, Kwon HJ and Kim MK (2009). Hypoglycemic effect of Chlorella vulgaris intake in type 2 diabetic GotoKakizaki and normal Wistar rats. Nutr. Res. Pract. 3: 23-30.

Jeon JY, Kwon JS, Kang ST, Kim BR, et al. (2014). Optimization of culture media for large-scale lutein production by heterotrophic Chlorella vulgaris. Biotechnol. Prog. 30: 736-743.

Machida T, Murase H, Kato E, Honjoh K, et al. (2008). Isolation of cDNAs for hardening-induced genes from Chlorella vulgaris by suppression subtractive hybridization. Plant Sci. 175: 238-246.

Miao X and Wu Q (2004). High yield bio-oil production from fast pyrolysis by metabolic controlling of Chlorella protothecoides. J. Biotechnol. 110: 85-93. 
Ngangkham M, Ratha SK, Prasanna R, Saxena AK, et al. (2012). Biochemical modulation of growth, lipid quality and productivity in mixotrophic cultures of Chlorella sorokiniana. Springerplus 1: 33.

Nguyen B, Bowers RM, Wahlund TM and Read BA (2005). Suppressive subtractive hybridization of and differences in gene expression content of calcifying and noncalcifying cultures of Emiliania huxleyi strain 1516. Appl. Environ. Microbiol. 71: 2564-2575.

O'Grady J and Morgan JA (2011). Heterotrophic growth and lipid production of Chlorella protothecoides on glycerol. Bioprocess Biosyst. 34: 121-125.

Perez-Garcia O, Escalante FM, de-Bashan LE and Bashan Y (2011). Heterotrophic cultures of microalgae: metabolism and potential products. Water Res. 45: 11-36.

Sauer N and Tanner W (1989). The hexose carrier from Chlorella cDNA cloning of a eucaryotic $\mathrm{H}^{+}$-cotransporter. FEBS Lett. 259: 43-46.

Shi X, Chen F, Yuan J and Chen H (1997). Heterotrophic production of lutein by selected Chlorella strains. J. Appl. Phycol. 9: 445-450.

Shen Y, Yuan W, Pei Z and Mao E (2010). Heterotrophic culture of Chlorella protothecoides in various nitrogen sources for lipid production. Appl. Biochem. Biotechnol. 160: 1674-1684.

Wakasugi T, Nagai T, Kapoor M, Sugita M, et al. (1997). Complete nucleotide sequence of the chloroplast genome from the green alga Chlorella vulgaris: the existence of genes possibly involved in chloroplast division. Proc. Natl. Acad. Sci. U. S. A. 94: 5967-5972.

Wicke S, Schneeweiss GM, dePamphilis CW, Muller KF, et al. (2011). The evolution of the plastid chromosome in land plants: gene content, gene order, gene function. Plant Mol. Biol. 76: 273-297.

Wolfe AD and dePamphilis CW (1997). Alternate paths of evolution for the photosynthetic gene rbcL in four nonphotosynthetic species of Orobanche. Plant Mol. Biol. 33: 965-977. 